\title{
Redesenho do logotipo Marias Bonitas: aplicação do design colaborativo
}

\section{Marias Bonitas' brand redesign: collaborative design application}

\author{
Nathalie Assunção Minuzi ${ }^{[1]}$, Leila Maria Santos Araújo ${ }^{[2]}$, \\ Giana Tondolo Bonilla ${ }^{[3]}$, Márcia Eliane Paixão[4]
}

\begin{abstract}
Resumo: Este artigo tem como objetivo apresentar o redesenho e posicionamento de marca do coletivo Marias Bonitas, localizado na cidade de Santa Maria - RS. A partir da demanda apresentada por um coletivo de mulheres, busca-se aplicar o redesenho por meio de uma estratégia colaborativa, juntamente com outras ações que promovam o desenvolvimento do coletivo. Como metodologia foi utilizada a abordagem do Design Thinking, onde o foco do projeto está centrado no usuário. Neste caso, as mulheres foram as responsáveis por redefinir a marca com o auxílio técnico de uma designer, e assim pensar seu posicionamento, considerando o desenvolvimento social desta localidade. Como resultado do redesenho da marca, houve uma maior aceitação deste posicionamento pelo coletivo e pela comunidade, e obtivemos um redesenho da identidade visual e um manual desta para o uso do grupo em seus produtos e nas redes sociais.
\end{abstract}

Palavras-chave: Design Thinking; mulheres; redesenho de logotipo

[1] Mestrado Acadêmico (Colégio Técnico Industrial), UFSM. nathalieminuzi@gmail.com

[2] Doutorado em Informática na Educação, UFRGS. leilamas@ctism.ufsm.br

[3] Graduação em Desenho Industrial, UFSM. gih.bonilla@gmail.com

[4] Doutorado em Educação, UNISINOS.marciapaixao12@gmail.com 


\begin{abstract}
This paper aims to introduce the brand redesign and the positioning of the Marias Bonitas brand, located in Santa Maria - RS. From the demand presented by a collective of women, it seeks to apply the redesign by means of a collaborative strategy, together with other projects that promote or develop the collective. The methodology used was the Design Thinking approach, where the focus of the project is centered in the user. In this case, the collective was responsible for redefining the brand, with the technical assistance of a graphic designer, and thus define the collective's positioning, considering the social development of this location. As a result of this redesign, there was increased acceptance of the brand by the collective and the community, and the result of the redesign provided a new visual identity and a manual for its use, used by the group in its products and social network.
\end{abstract}

Keywords: Design Thinking; women; brand redesign

\title{
INTRODUÇÃO
}

O design estratégico é uma ferramenta utilizada em diversos níveis e tem sido explorado na perspectiva organizacional de empresas e associações. O designer deve perceber as demandas da sociedade a fim de propor melhorias de produtos e serviços baseando-se no conhecimento técnico e prático, e nesse ponto o design entra não só como uma estratégia visual, mas também de posicionamento social e de marketing.

No que concerne ao desenho de marca, existe uma demanda latente para que essa acompanhe as mudanças de quem ou o quê ela busca representar. Esta representação deriva de um planejamento, com o objetivo de posicionamento de um grupo ou uma empresa frente aos seus clientes. A partir dessa ótica, é preciso pensar nos elementos gráficos da marca e de que maneira essa representação gráfica irá comunicar seu produto ou serviço.

O redesenho do logotipo surge como uma demanda geralmente vinda do mercado. Nesse sentido, o design social compreende que a questão do impacto das mudanças em um nível local desperta um olhar centrado no usuário, sem perder a ideia do contexto social, no qual as demandas estão inseridas.

Uma marca, entre outras coisas, serve para referenciar uma determinada comunidade em relação a um contexto mais abrangente. Neste sentido, o domínio deste trabalho advém de uma demanda apresentada por um grupo de mulheres 
que está em vias de formalizar sua associação, que tem como objetivo a geração de renda e a formação dessas mulheres.

O redesenho da marca deste grupo resulta de um conjunto de ações planejadas para fomentar o empreendedorismo entre as mulheres participantes do grupo. Contudo, este trabalho irá se ater apenas do redesenho do logotipo, objetivando apresentar o processo criativo realizado de maneira coletiva, enfatizando as possibilidades da criação colaborativa no design social.

\section{METODOLOGIA}

Este trabalho se baseou na metodologia Design thinking, proposto por Tim Brown (2008), que tem como objetivo desenvolver produtos e serviços baseados nas necessidades do usuário.

O design thinking utiliza como ferramenta o double diamond, que está categorizado em cinco fases denominadas: empatia, definição, idealização, prototipagem, testagem.

A fase de empatia se refere aos primeiros contatos com o grupo, ou seja, serviu para conhecer o contexto onde seria trabalhada esta ação. O grupo Marias Bonitas se caracteriza por ser um grupo de mulheres que tem como objetivo gerar renda por meio da venda de produtos artesanais. A definição diz respeito a delimitar a demanda a ser trabalhada, ou seja, compreender por qual razão seria necessário redesenhar este logotipo, considerando que existiam fatores que o grupo prezava e que deveriam ser mantidos neste novo desenho. A idealização foi a definição do problema: como redesenhar o logotipo do grupo Marias Bonitas, mantendo os requisitos pelo grupo. Já a prototipagem, diz respeito a fase onde se desenvolveu o processo de redesenho propriamente dito, com várias alternativas que foram discutidas em grupo, dentro do que havia sido pedido; em seguida o logotipo final foi finalizado. Por último, a testagem foi feita através do uso do logotipo nas redes sociais do coletivo, evidenciando um novo capítulo na história do grupo e convidando a comunidade a conhecer a nova marca e o novo posicionamento das integrantes em relação aos seus produtos. 
Esta ferramenta serviu para analisar a demanda das mulheres em relação ao redesenho do logotipo e realizar o desenvolvimento e implementação do mesmo nos produtos que estavam sendo comercializados. A partir de um processo colaborativo entre pesquisadora, designer e participantes do grupo, foi possível chegar a um denominador comum: o redesenho do logotipo para o grupo.

A principal ferramenta utilizada para o levantamento de requisitos para este redesenho foi o brainstorming, onde as participantes puderam opinar e realizar a tomada de decisões em relação ao novo desenho. A partir das decisões conjuntas, foi possível executar esta implementação gráfica aos produtos que eram vendidos.

\section{DESENVOLVIMENTO}

O desenvolvimento deste trabalho ocorreu em função de cinco ações construídas para a associação Marias Bonitas. Tais ações tinham o cunho de posicionamento desta associação para melhorar a visibilidade de seus produtos na comunidade onde vivem. Para realizar esta efetivação, uma das ações foi a de redesenhar o logotipo da associação em vista de proporcionar mais visibilidade para o grupo em relação a sua comunidade e para que o coletivo pudesse alcançar novos nichos de mercado.

Para a American Marketing Association (AMA) marca é "um nome, termo, símbolo, desenho ou uma combinação desses elementos que deve identificar os bens ou serviços de uma empresa ou grupo de empresas e diferenciá-los dos da concorrência" (GARDNER; LEVI, 1955 apud SERRALVO, 2008). A partir da interação destes elementos observou-se a necessidade do redesenho.

Neste caso, percebeu-se na marca do grupo uma estratégia de popularizar-se na comunidade onde estava alocado e visar novos mercados por meio do alcance das redes sociais. Para que isso ocorresse era necessário buscar um desenho que projetasse o grupo além da sua comunidade. 
De acordo com a Organização Mundial de Propriedade Intelectual (OMPI), uma marca "é um signo que permite diferenciar os produtos ou serviços de uma empresa dos demais" (OMPI, 2006, p.3).

Elas podem ser representadas por meio de palavras, letras, números, desenhos, fotos, ou ainda ser a combinação destes elementos com a finalidade de diferenciação. Entende-se que o conceito de "marca" atualmente está ligado ao conceito de branding. Parafraseando Tomiya:

De fato, sob a ótica de uma análise exclusiva do processo de decisão de escolha de compradores no supermercado da vida (em quase todos os pro- cessos de decisão de compra), a marca leva a uma imediata diferenciação no processo de decisão de compra. Marcas não são somente nome, logotipo, embalagem e design. Marcas fortes são construídas através da sua experiência total, ou seja, de um histórico consistente de promessa e entrega (TOMIYA, 2014, p.16).

O branding dentro de uma instituição, é elementar para compreender os processos de gestão e estratégia de marca. Este arcabouço teórico é necessário para entender a importância da marca dentro de uma associação ou empresa. De acordo com Tomiya,

O branding é um processo estruturado, consistente e integrado, que garante a melhoria contínua da entrega da promessa da marca, desde a definição dessa promessa até a implementação em todos os seus pontos de contato com os públicos estratégicos (TOMIYA, 2014, p.22).

Estes conceitos, foram apresentados ao grupo como uma justificativa para modificar o logotipo, a fim de desenvolver uma representação simplificada do desenho que já estava sendo utilizado pelo grupo.

O principal argumento para esta modificação esteve no fato de buscar um símbolo que representasse esta nova fase do grupo, ou seja, como uma maneira de marcar a consolidação da associação. Na perspectiva de Geissbuhler 
Descobrimos que nossos públicos reagem de forma mais direta e emotiva a símbolos reconhecíveis e ícones culturais que tenham conotações, características e qualidades bem claras. A marca comercial, mesmo sendo um elemento chave da maior importância, nunca pode contar toda a história. Quando muito, ela transmite uma ou duas noções ou aspectos da empresa. A identidade tem que estar apoiada em uma linguagem visual e em um vocabulário (WHEELER, 2012, p.135).

Esta visão do designer juntamente com o conhecimento técnico serviu como justificativa para realizar esta ação. Redesenhar o logotipo foi a ação mais extensa de ser implantada no grupo, pois houve a necessidade de fazer uma reunião para explicar a razão pela qual o coletivo deveria redesenhar seu logotipo.

Para isso, foi necessário adotar uma abordagem que estivesse condizente com o atual posicionamento do grupo, em relação aos produtos e serviços que passarão a ser oferecido aos seus clientes.

A partir disso, foi realizada uma nova reunião com o grupo, a fim de explanar sobre a importância da marca para um empreendimento. Assim foi possível iniciar um processo de brainstorming coletivo, onde todas as integrantes do grupo puderam opinar sobre o que esperavam que o logotipo representasse para no grupo.

Após este primeiro processo, uma designer foi convidada para repetir o exercício e realizar uma lista de requisitos para redesenhar o logotipo. É relevante apresentar que a designer esteve presente durante todas as fases do processo.

$\mathrm{Na}$ imagem abaixo é possível ver o primeiro logotipo do grupo Marias Bonitas.

Esta imagem, de acordo com as integrantes, representa a união entre elas. Para o desenvolvimento do logotipo novo, essa informação foi considerada como um requisito, junto a outros pedidos realizados pelas integrantes, a fim de gerar uma imagem que refletisse os valores do coletivo para os consumidores destes produtos. 


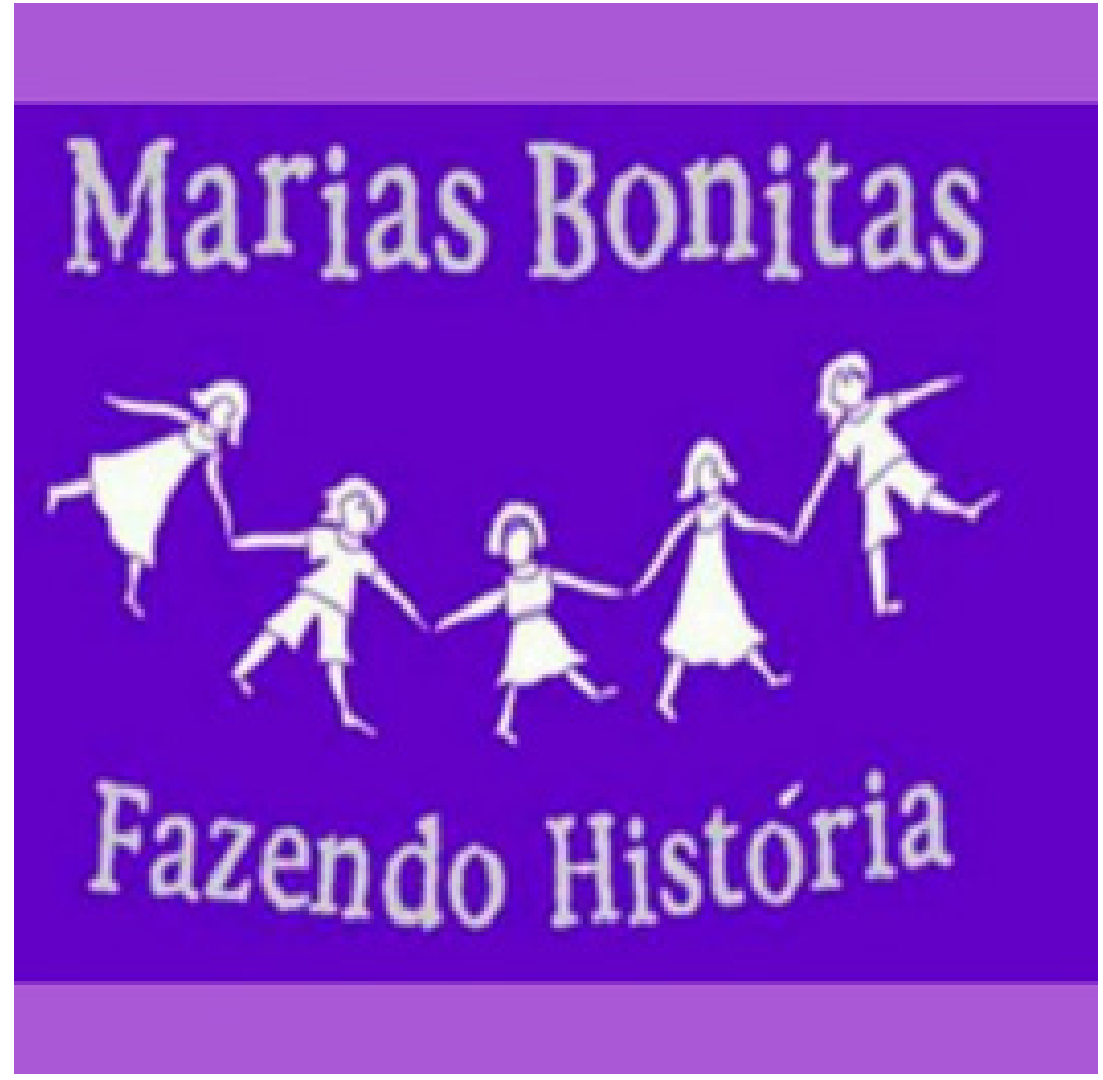

Outro ponto que merece realce é que o grupo já possui um histórico com esta imagem, e as integrantes se encontraram relutantes em se desfazer do desenho antigo, por isso foi sugerido um redesenho em vez de fazer um novo logotipo do zero. Uma das preocupações do coletivo é que a identidade que elas já tinham construído se perdesse, e que a comunidade demorasse a associar o novo desenho ao velho, por isso algumas exigências visuais foram mantidas, como a cor e a representação gráfica de pessoas.

Durante todo este processo enfatizou-se a necessidade de gerar uma síntese gráfica, para que os usuários se identifiquem com a mesma, gerando uma imagem que utilizasse menos insumos para a sua apresentação. De acordo com Furrier:
Figura 1: Logo do grupo Marias Bonitas. Fonte: Imagem cedida pelo grupo. 
Para se destacar das outras, cada marca se utiliza de diferenças localizadas, as quais podem ser convertidas em importantes vantagens psicológicas. Os esforços de promoção de uma marca ajudam a construir o intervalo entre o custo de um produto e o seu valor percebido (FURRIER, 2008, p. 164).

Em um conceito de valorização mercadológica (ideia de concorrência) as marcas têm um papel fundamental, como aponta o autor; porém, esse não era o objetivo desta pesquisa. Nas imagens abaixo, é possível observar a etapa de rascunhos do redesenho.
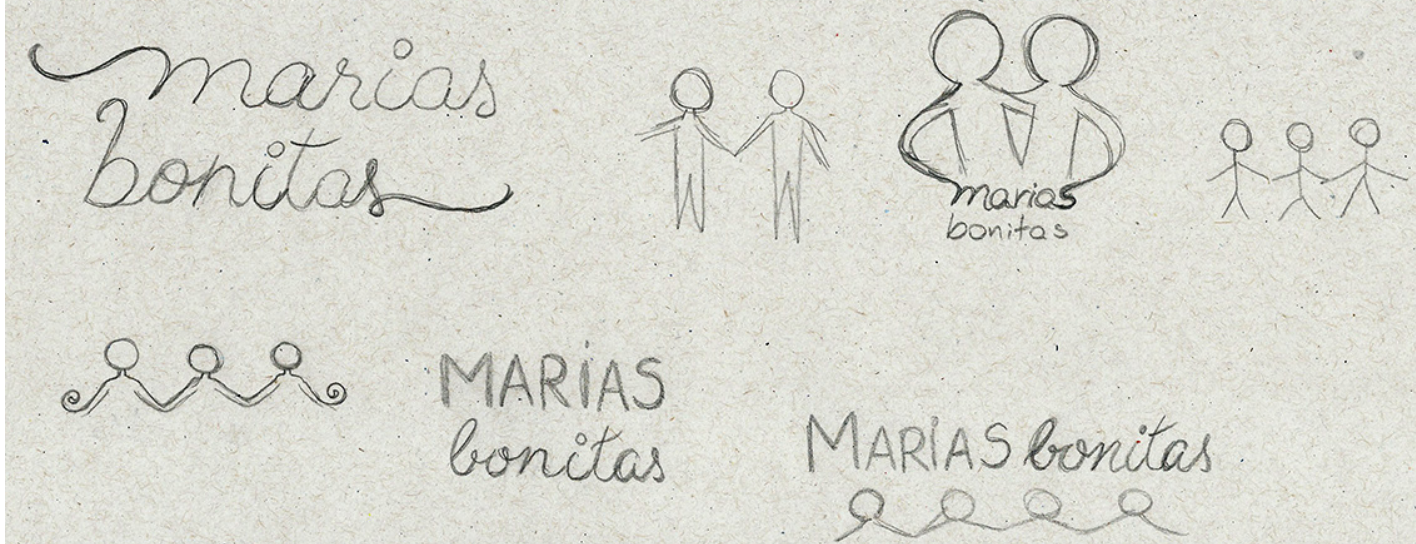

cmarias

bonitas.
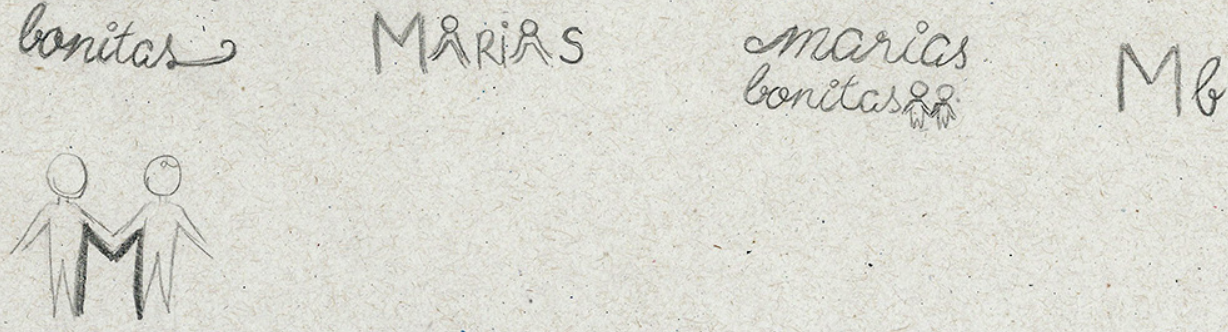

Figura 2 Desenvolvimento da ideia do logo. Fonte: Elaborado pela designer.

As integrantes foram firmes quanto ao conteúdo do desenho em si. Era necessário que se mantivesse a síntese gráfica de pessoas e que, diferente do logotipo antigo, os "bonecos" não tivessem cabelos ou roupas, pois as integrantes sentiam que isso dava um espaço para interpretações espe- 
cíficas de gênero, e seria melhor que todo mundo se sentisse representado com o desenho.

Outra exigência era passar a sensação de união e acolhimento, já que se trata de um coletivo de mulheres que visa o emponderamento feminino e a capacidade de cada uma de gerar renda para si própria e/ou para sua família. Ao apresentarmos para o grupo estes desenhos, juntamente com a escrita da marca, começou a segunda parte do processo.

Inicialmente foram apresentadas duas alternativas para o logotipo: feito na mão e feito no computador. O coletivo escolheu as versões feitas a mão, com caligrafia de pincel, pois isso lembra o artesanato, que foi o chute inicial para a criação do coletivo.

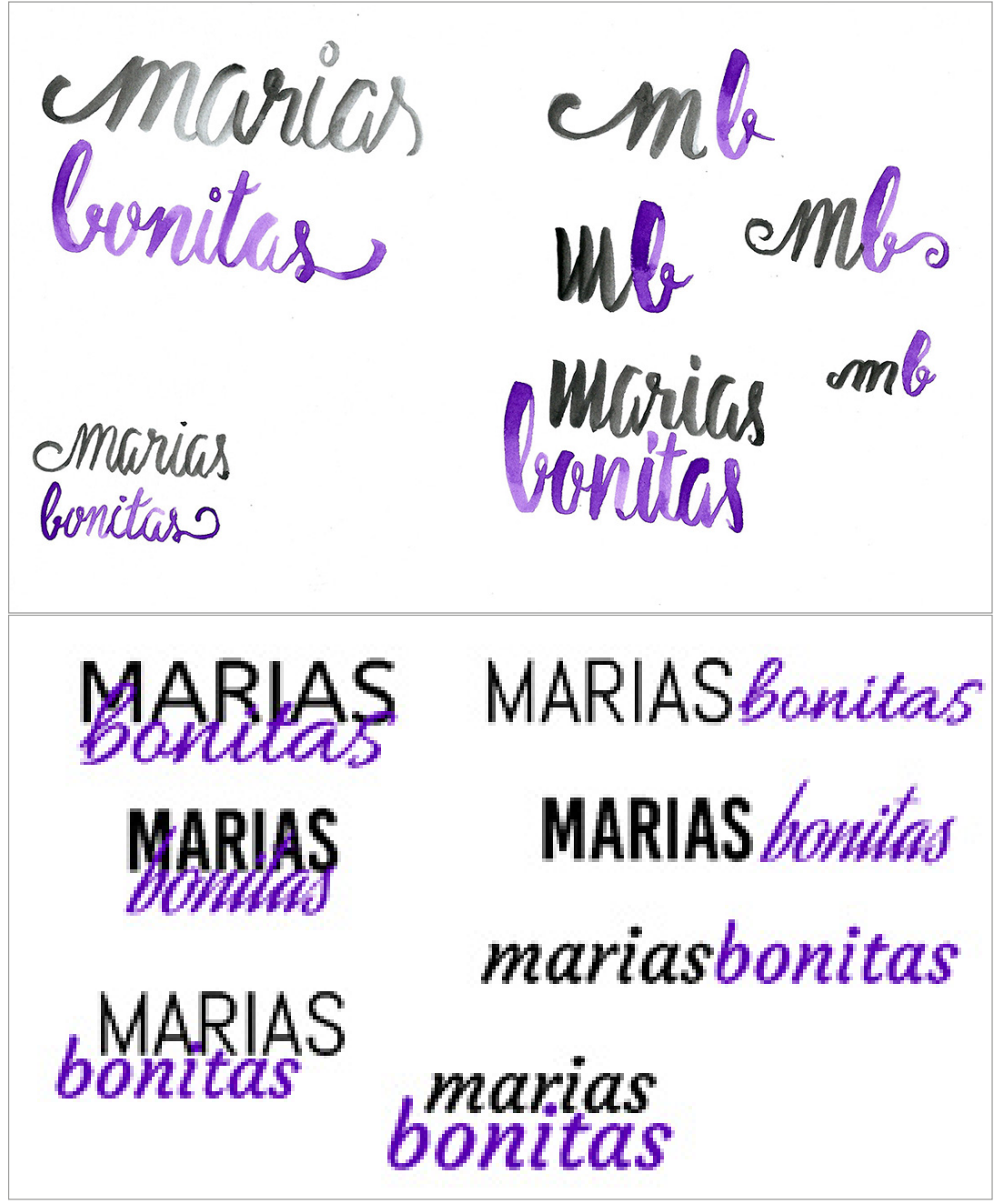

Figura 3: Desenvolvimento das alternativas. Fonte: Elaborado pela designer. 
Após esta escolha, iniciou-se o processo de acabamento realizado de maneira digital, onde a designer utilizou as cores escolhidas pelas clientes, gerando assim as versões finais a serem apresentados para o coletivo.

Procurou-se pensar nessa mudança de logotipo baseada em um princípio de reposicionamento do grupo, agora como uma associação, e na economia para a produção de seus materiais como: cartazes, panfletos, embalagens, etc. Neste sentido vemos de maneira intrínseca a justificativa ambiental para desenvolver materiais que diminuam o seu impacto no meio ambiente.

$\mathrm{Na}$ imagem abaixo, podemos observar o resultado principal do logotipo, com a aprovação do coletivo.

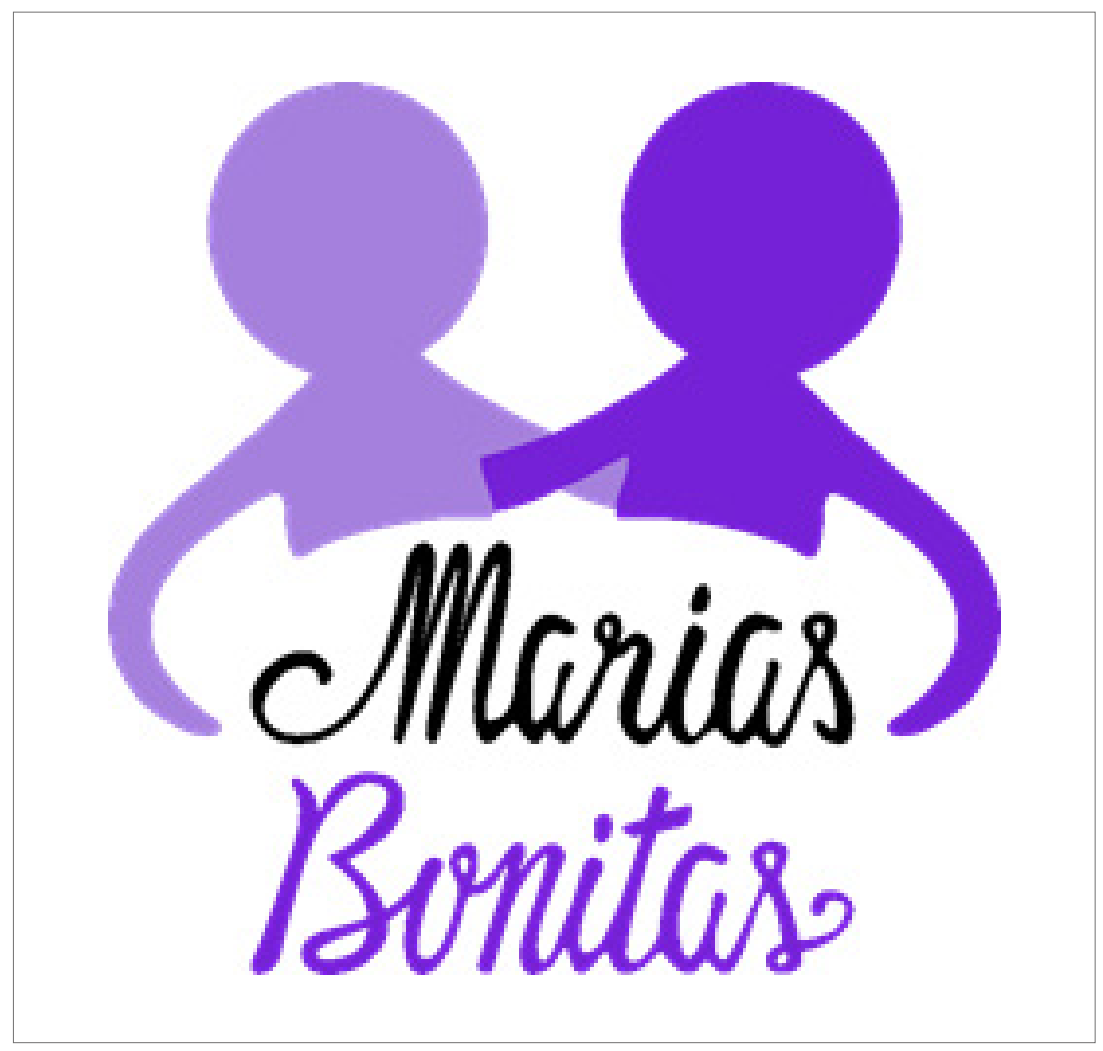

Figura 4: Logotipo na versão colorida. Fonte: Elaborado pela designer.

Além do logotipo principal, foram feitas outras versões, como preto e branco, preto e cinza, etc. para o uso variado, tanto em produtos físicos como redes sociais. Também foi 
apresentado um manual da marca, com instruções simples de como usar as diferentes cores apresentadas, assim como margens mínimas e tamanho mínimo.

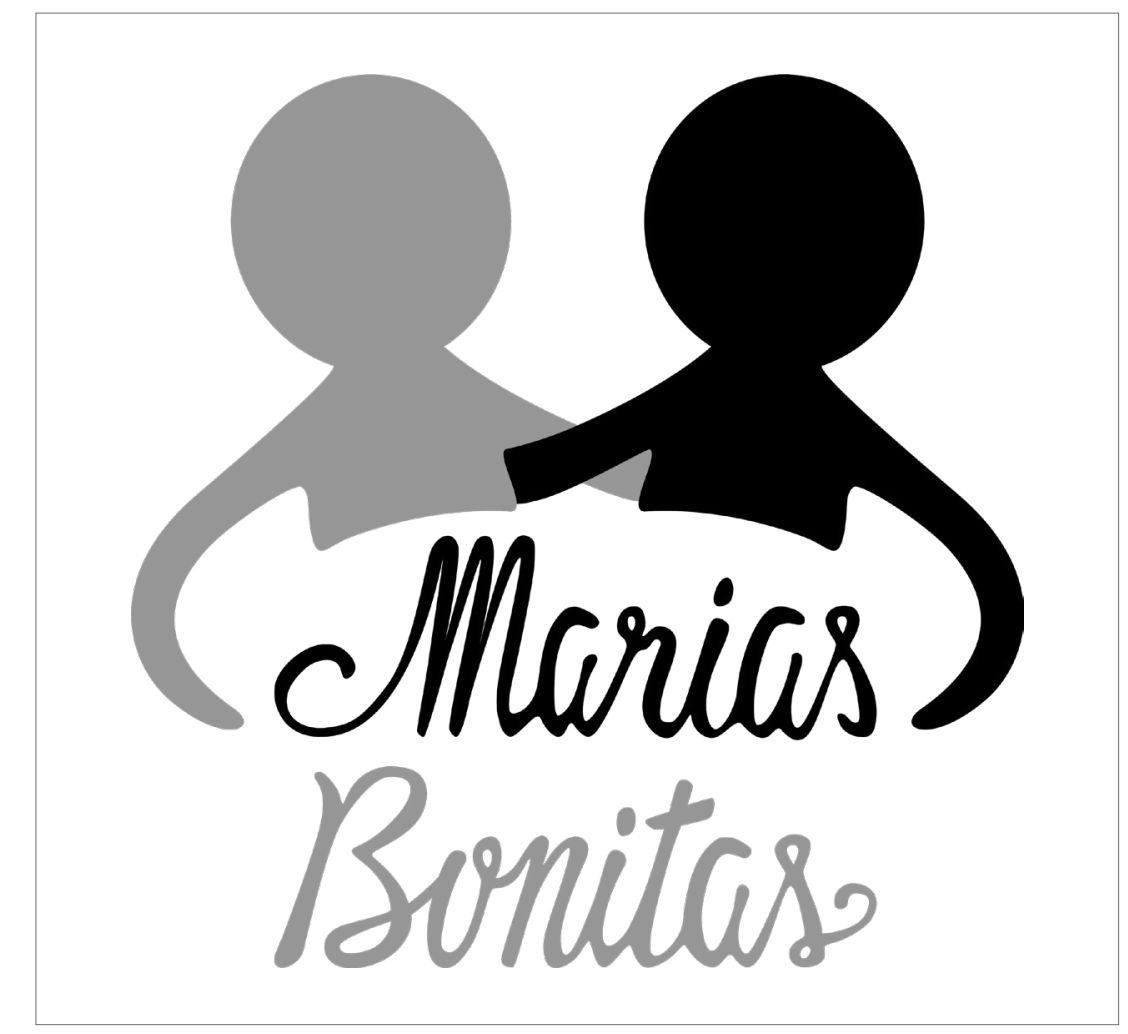

Figura 5: Logotipo final na versão preto e cinza. Fonte: Elaborado pela designer.

Esta ação foi implementada com bastante êxito, uma vez que as participantes se identificaram e se sentiram representadas com a marca. Contudo, será necessário que, futuramente, haja um trabalho em etapas para efetivação da marca em todos os materiais gráficos e redes sociais mantendo métricas para mensurar o alcance deste novo desenho. Como estratégia serão realizadas enquetes, via redes sociais com os clientes sobre o desenho do logotipo.

\section{RESULTADOS E DISCUSSÃO}

Ao buscar desenvolver o redesenho de um logotipo, é necessário compreender a complexidade de tal tarefa. Nesta pes- 
quisa o redesenho do logotipo não foi uma ação isolada, mas sim uma das ações estratégicas que visam visibilizar a associação Marias Bonitas como uma entidade que gere renda para as participantes envolvidas. Isto corrobora o conceito de branding que é responsável pela construção da estratégia de posicionamento da marca. Ratificando o pensamento de TOMIYA (2014) que afirma que o "logotipo, o nome e a comunicação são consequências de uma estratégia" (TOMIYA, 2014, p.17).

De acordo com Brown (2008) o design thinking é capaz de integrar essas variantes de acordo com a necessidade do projeto, desde que todos estejam envolvidos com a demanda apresentada.

A construção colaborativa foi um dos principais desafios existentes nesta pesquisa uma vez que foi necessário explicar aspectos técnicos do design para pessoas que desconheciam a fim de gerar o redesenho de modo satisfatório. Isto resultou no envolvimento do grupo com a designer, onde houve uma liberdade estética para a criação do desenho.

Tal envolvimento foi percebido durante todo este processo, isto ocorreu porque se decidiu realizar um trabalho centrado nas pessoas que iriam utilizar o logotipo, como é apontado dentro do processo de design thinking. Foi perceptível o envolvimento das participantes resultando na aceitação por parte do grupo. Comparando com o primeiro desenho que o grupo já utilizava, percebeu-se que é possível ao se planejar as etapas do projeto e com a geração de alternativa, obtermos resultados efetivos quando corretamente aplicados.

Neste sentido, o redesenho deste logotipo surgiu de uma demanda social, solicitado por um grupo de mulheres com o objetivo de visibilizar sua associação. A partir destas construções observa-se como a participação de um profissional que trabalhe próximo a comunidade pode gerar um bom resultado, considerando a construção social do grupo, ou seja, foi necessária uma compreensão da designer para realizar o processo de construção deste desenho. Isto foi relevante pois, o redesenho deveria além de ser aprovado, deveria ser implementado pelo grupo para que esta ação fosse de fato efetivada. 
É importante salientar que o processo de experiência do usuário tem sido cada vez mais explorado e por esta razão, houve esta necessidade em redesenhar o logotipo. Neste sentido corrobora-se a ideia de Tomiya (2014) que a marca não se detém ao logotipo, ao nome ou a propaganda, mas sim a união destes elementos, assim este trabalho foi conduzido pelo processo de design, apresentando no redesenho do logotipo uma solução satisfatória que completa as outras ações de posicionamento da marca desta associação na comunidade na qual está inserida.

\section{CONCLUSÃo}

O redesenho do logotipo serviu como um elemento para fomentar o crescimento do coletivo na venda dos produtos artesanais. Ao redesenhar este logotipo, estamos afirmando este grupo não somente como uma associação, mas como um local para o crescimento pessoal das associadas.

Neste ponto foi relevante todo o processo de construção colaborativa entre pesquisadora, designer e todas as integrantes para chegar ao desenho final. A pesquisadora e designer foram as responsáveis por apresentar os meios de visibilizar a associação para a comunidade enquanto as participantes foram delineando o estudo ao apresentarem as demandas, principalmente para este redesenho.

Observou-se como positivo a construção coletiva que ocorreu durante o processo de redesenho do logotipo, uma vez que estas mulheres se sentiram parte do projeto, colaborando com a designer a cada etapa para chegar a um resultado satisfatório para todas as partes. Este fato serve para pesquisas futuras que visem trabalhar com esta construção colaborativa em instituições. 
A partir deste trabalho percebeu-se a relevância, dentro do viés social, em desenvolver projetos onde as clientes sejam partes ativas no processo de criação, principalmente partindo do princípio de que o coletivo não tinha experiência com identidade visual ou marketing. Para isto foi necessário um processo de apresentação conceitual sobre a importância do logotipo para a associação, o que foi fundamental para que as próprias integrantes desenvolvessem seu senso estético em relação a um desenho de logotipo.

Durante este estudo observou-se a necessidade de projetos que contemplem a realidade do cliente. Neste caso foi a associação em face de existir uma implementação deste novo logotipo. Acredita-se que só houve esta implementação, pois, o processo foi colaborativo. Neste sentido é necessário cada vez mais a aproximação entre projetos que derivam de uma demanda e a sociedade que irá utilizá-los.

\section{REFERÊNCIAS}

BROWN, T. Design Thinking. Disponível em: https:// emprendedoresupa.files.wordpress.com/2010/08/p02_ brown-design-thinking.pdf. Acesso em: 10, jul. 2018.

FURRIER, M. T. Posicionamento e reposicionamento

de marcas. In: Gestão de Marcas no contexto brasileiro. SERRALVO. F. A.(org.). São Paulo: Saraiva, 2008.

OMPI, Organización Mundial de la propriedad intelectual. Disponível em: http://www.wipo.int/ wipo_magazine/es/2006/01/. Acesso em: 18, abr. 2018.

TOMIYA, E. Branding Analítico: Métodos

Quantitativos para Gestão da Marca.

São Paulo: ATLAS S.A, 2014.

WHEELER. A. Design de identidade da marca:

guia essencial para toda a equipe de gestão de marcas. Porto Alegre: Bookman, 2012. 